\title{
The effects of combined sertraline and aspirin therapy on depression severity among patients with major depressive disorder: A randomized clinical trial
}

\section{Zahra Sepehrmanesh ${ }^{1}$, Hosein Fahimi ${ }^{2}$, Goudarz Akasheh ${ }^{3}$, Mohamadreza Davoudi ${ }^{4}$, Hamidreza Gilasi ${ }^{5}$, Amir Ghaderi $^{6}$}

\footnotetext{
${ }^{1}$ M.D, Psychiatrist, Associate Professor, Department of Psychiatry, School of Medicine, Kashan University of Medical Science, Kashan, Iran

${ }^{2}$ M.D, Psychiatrist, Department of Psychiatry, School of Medicine, Kashan University of Medical Science, Kashan, Iran

${ }^{3}$ M.D, Psychiatrist, Assistant Professor, Department of Psychiatry, School of Medicine, Kashan University of Medical Science, Kashan, Iran

${ }^{4}$ M.Sc. Student of Clinical Psychology, Student Research Committee, Kashan University of Medical Sciences, Kashan, Iran

${ }^{5}$ Ph.D., Associate Professor, Health Information Management Research Center, Kashan University of Medical Sciences, Kashan, Iran

${ }^{6}$ Ph.D. Candidate of Addiction Studies, Student Research Committee, Kashan University of Medical Sciences, Kashan, Iran
}

\section{Type of article: Original}

\begin{abstract}
Background: Different studies have been conducted to find the best adjuvant therapies for depression management. There are controversies over the effects of aspirin as an adjuvant therapy for depression.

Objective: To determine the effects of combined sertraline and aspirin therapy on depression severity among patients with major depressive disorder.

Methods: This randomized clinical trial was conducted at Kargarnejad Psychiatric Hospital in Kashan, Isfahan, Iran, from September 1, 2016 to November 1, 2016. The study participants included 100 patients with major depressive disorder who were assigned to aspirin and placebo groups by the use of computer-generated random numbers. Patients in these groups respectively received sertraline-aspirin and sertraline-placebo for eight consecutive weeks. Patients were prescribed 80 milligrams of aspirin twice a day. Also, sertraline was administered at a dose of 50-200 milligrams daily. Beck Depression Inventory was employed for depression severity assessment at four time points, namely before, two, four, and eight weeks after the beginning of the intervention. Medication side effects were also assessed eight weeks after the beginning of the intervention. Data were analyzed by SPSS version 12.0, using Chi-square and the Independent-samples t-test $(\alpha=0.05)$.

Results: Both groups were matched in terms of age $(\mathrm{p}=0.46)$, gender $(\mathrm{p}=0.539)$, and depression severity ( $\mathrm{p}=0.509$, with mean score $33.5 \pm 4.1$ vs. $32.8 \pm 5.9$ ) at baseline. However, depression scores were reduced significantly four and eight weeks after initiation of therapy just in the sertraline-aspirin group $(\mathrm{p}<0.05)$.

Conclusion: As an adjuvant therapy, aspirin can reduce depression severity among patients with major depressive disorder. Yet, further studies are needed to prove the effectiveness of aspirin and other antiinflammatory agents in reducing depression severity.

Trial registration: The trial was registered at the Iranian Registry of Clinical Trials (http://www.irct.ir) with the IRCT ID: IRCT2016082829556N1.

Funding: The authors received financial support from Research Deputy of Kashan University of Medical Sciences, Kashan, Isfahan, Iran

Keywords: Sertraline, Depression, Aspirin
\end{abstract}

\section{Corresponding author:}

Dr. Hosein Fahimi, Department of Psychiatry, School of Medicine, Kashan University of Medical Science, Kashan, Iran. Tel: +98.3155540021; Email: hossein1fahimi@gmail.com

Received: August 29, 2017, Accepted: October 25, 2017, Published: November 2017

iThenticate screening: October 16, 2017, English editing: November 12, 2017, Quality control: November 15, 2017 This article has been reviewed / commented by four experts

(C) 2017 The Authors. This is an open access article under the terms of the Creative Commons Attribution-NonCommercialNoDerivs License, which permits use and distribution in any medium, provided the original work is properly cited, the use is non-commercial and no modifications or adaptations are made. 


\section{Introduction}

Major depressive disorder (MDD) is one of the leading causes of disability (1). It accounts for $2 \%-4 \%$ of global disability-adjusted life years $(1,2)$. Around the world, four per 100 persons suffer from $\operatorname{MDD}(3,4)$. In fact, with a prevalence of $17 \%$ depressive disorder, it is the most prevalent psychiatric disorder in the world, hence it is called the "common cold" of psychiatric conditions $(5,6)$. Depression leads to different consequences such as disability, low quality of life, sleep disorders, academic failure, marital conflicts, and suicide (6). Moreover, due to disability, depressed individuals become a burden to their societies. Thereby, given the high prevalence of MDD and MDDinduced disability, MDD annually causes billions of dollars of economic damage worldwide (7). It also aggravates illnesses such as asthma, diabetes mellitus, and arthritis (8). More seriously, MDD is associated with a high prevalence of suicidal and even homicidal thoughts $(6,9)$. Therefore, prompt treatment is needed to promote depressed people's functional status, and reduce the risk of suicide and homicide. There are two main approaches to MDD management, namely medication therapy and psychotherapy $(10,11)$. The most important psychotherapies are cognitive behavioral therapy $(12,13)$ and mindfulness-based therapies (such as Acceptance and commitment therapy and Dialectical behavior therapy) both of which have been known to have significant effects on MDD (14, 15). On the other hand, the most important medications for MDD management are tricyclic antidepressants, monoamine oxidase inhibitors, and serotonin reuptake inhibitors $(16,17)$. As one of the inhibitors of serotonin reuptake, sertraline is the best treatment option for the improvement of MDD symptoms (8). Recently, depression symptoms were found to have a reciprocal relationship with inflammation (18). Moreover, autoimmune disorders (such as rheumatoid arthritis) and infectious diseases (such as hepatitis) have been found to dramatically heighten the risk for developing depression $(19,20)$. The prevalence of depression among hospitalized patients with autoimmune disorders and infectious diseases was reported to be $45 \%$ and $62 \%$, respectively (21). In addition, more than one fourth of patients who receive interferon (a medication for hepatitis $\mathrm{C}$ which causes serious inflammation) develop depression (22).Moreover, high levels of peripheral inflammatory markers (such as C-reactive protein, tumor necrosis factor alpha, and interleukin) were observed among depressed patients who suffered from no comorbid physical problems, denoting the probable effects of inflammation on depression (23). However, despite the known effectiveness of antidepressant medications and psychotherapy in alleviating the symptoms and the severity of MDD, these modalities have no significant effects on inflammation and cannot alleviate inflammatory symptoms which can affect depression (23). Aspirin is a non-steroidal anti-inflammatory drug (NSAID) which inhibits cyclooxygenase (24). As one of the most important structural enzymes, cyclooxygenase has a significant role in the production of inflammatory mediators such as prostaglandin, prostacyclin, and thromboxane (25). Thus, pharmacological inhibition of cyclooxygenase can alleviate inflammatory symptoms (26). Besides its contribution to pain and inflammation, cyclooxygenase is assumed to be involved in neural degenerative disorders associated with depression (27). Antidepressants and anxiolytic agents have slight, if any, effects on inflammation (28), and hence, the treatment of choice for the management of depression-related inflammatory symptoms would be antiinflammatory agents (29). Previous studies into the effects of anti-inflammatory drugs on depression symptoms, reported contradictory results. The main reasons behind these contradictions have been the selection of patients from certain age groups $(30,31)$, the administration of aspirin in association with inappropriate antidepressants (such as citalopram instead of sertraline) (32) and the use of NSAIDs instead of aspirin (33). The present study was done to remove the effects of such confounders and investigate the effects of combined sertraline and aspirin therapy on depression severity among patients with MDD.

\section{Material and Methods}

\subsection{Trial design}

This study was a randomized clinical trial that was conducted from September 1, 2016 to November 1, 2016.

\subsection{Participants}

This clinical trial was conducted in an Iranian governmental educational hospital (Kargarnejad Psychiatric Hospital). Kargarnejad Psychiatric Hospital is the largest psychiatric center in Kashan, Isfahan, Iran, and it is affiliated with Kashan University of Medical Sciences. The research population was comprised of patients with major depression disorder diagnosis who referred to Kargarnejad Psychiatric Hospital.

\subsection{Selection criteria}

Eligibility criteria were an age of more than forty, a definite diagnosis of MDD based on the criteria reported in the Diagnostic and Statistical Manual of Mental Disorders (DSM-IV), no history of NSAID use or mania, no history of alcohol or drug abuse during the past six months preceding the study, no contraindication for aspirin therapy (such as gastric ulcer), and no affliction by the risk factors of cardiovascular and neurologic diseases. Patients who became 
pregnant (Examined by home pregnancy tests (HPTs) during the study, who were unwilling to stay in the study and use other NSAID during the study, were excluded.

\subsection{Interventions}

Patients in the aspirin group received sertraline and aspirin while their counterparts in the placebo group received sertraline and placebo. In both groups, sertraline (Sobhan Pharmaceutical Co. Iran) was administered at a dose of 50 to 200 milligrams daily at the discretion of a psychiatry resident (i.e. the first author). Aspirin (Pars Darou Pharmaceutical Co. Iran) was also administered to patients in the aspirin group at a dose of 80 milligrams twice a day. Patients in the placebo group received placebo tablets (Pars Darou Pharmaceutical Co. Iran) which were in the shape and size similar to aspirin tablets.

\subsection{Outcomes}

Depression symptom severity, psychiatric condition, and sertraline side effects were respectively assessed using Beck Depression Inventory, Structured Clinical Interview for DSM-IV disorders, and a sertraline side effect checklist.

2.5.1. Beck Depression Inventory (BDI):

BDI is a 21-item inventory for assessing depression symptoms. The total BDI score is 0-63 and is interpreted as follows: 0-9: minimal depression; 10-18: mild depression; 19-29: moderate depression; and 30-63: severe depression. The one-week test-retest correlation coefficient of BDI is 0.93. Moreover, BDI score significantly correlates with the scores of the Hamilton Depression Rating Scale, the Minnesota Multiphasic Personality Inventory, and the Symptom Checklist-90 ( $r>0.60)$. BDI was also used in our country, Iran, and was reported to have a Cronbach's alpha of 0.70-0.90 (34).

2.5.2. Structured Clinical Interview (SCI) for DSM-IV disorders.

As a semi-structured interview, SCI for DSM-IV disorders is used to diagnose psychiatric disorders based on the criteria of DSM-IV (35). It was translated into Persian and cross-culturally adapted for the Iranian context. The Persian SCI was found to have a high agreement with the results of clinical psychiatric evaluators' judgments about psychiatric diagnoses (Kappa's agreement coefficient greater than 0.60) (35).

2.5.3. Sertraline side effect checklist:

This checklist was produced by the first author based on the side effects of sertraline reported in pharmacology textbooks. The checklist contained side effects such as fatigue, sleep disorders (mainly insomnia), mild nausea, diarrhea, gastric discomfort, dry mouth, common cold symptoms (such as nasal congestion and sneezing), increased perspiration or urination, weight changes, and sexual problems (such as decreased libido). This checklist was completed for each patient eight weeks after the beginning of the study intervention. The presence of each side effect was documented by placing a checkmark in front of it in the checklist (8). The data on depression severity and response to treatment were collected at four time points, namely before, two, four, and eight weeks after the beginning of the intervention.

\subsection{Sample size}

Based on the results of an earlier study (36), a type I error of 5\%, and a power of $80 \%, 47$ patients were determined to be needed for each study group. However, given the likelihood of dropouts, fifty patients were recruited to each group. Sampling was done consecutively because only a limited number of patients referred to the study setting each day.

\subsection{Randomization and blinding}

Recruited patients were randomly assigned to aspirin $(n=50)$ and placebo groups (50) using block randomization technique with four-patient blocks. Random assignment was done by the one of the researchers in the team, while study intervention was implemented by another researcher in the team. In other words, Hossein Fahimi was aware while Mohammad Reza Davoudi was blind to group assignment and intervention. Moreover, all participants were blind, whether they were in the aspirin or the placebo group.

\subsection{Statistical methods}

Collected data were analyzed via the SPSS software (v. 12.0) (SPSS Inc., Chicago, Illinois, USA) and through performing the Chi-square and the Independent-samples t-test. Results were reported using descriptive statistics such as mean, standard deviation, and absolute and relative frequencies. Significance level was set at less than 0.05 . 


\subsection{Research ethics}

The proposal for this thesis research was presented to the Ethics Committee of Kashan University of Medical Sciences after its scientific approval by the psychiatric department. The Ethics Committee approved the study with the number IR.KAUMS.REC.1394.37 on June 11, 2015, and the enrollment of patients began on September 1, 2016, and the study continued until November 1, 2016. This study was also registered in the Iranian Registry of Clinical Trials (irct.ir) with the ID: IRCT2016082829556N1. It should also be noted that we registered the study in irct.ir as a retrospective registration because we were allowed to conduct the thesis after the approval of the Ethics Committee, which is affiliated with the Office of the Vice Chancellor for Research at Kashan University of Medical Sciences. Also, all the authors confirm that all ongoing and related trials for this drug are registered. Indeed, in this study, for research ethical considerations, the participants were informed about the objective and nature of the study, and each participant provided her written consent prior to the study. Also, we were committed to keeping all the participants' information and date confidential.

\section{Results}

Initially, fifty patients were recruited to each study group, 100 in total. None of them left the study and thus, data analysis was done on the data collected from all 100 patients (Figure 1). On average, patients in the aspirin and the placebo groups were aged $48.9 \pm 7.5$ and $47.8 \pm 7.3$, respectively. No significance between-group difference was observed regarding patients' age, gender, marital and educational status, monthly income, and depression-anxiety comorbidity $(\mathrm{p}<0.05$; Table 1$)$. Table 2 shows depression severity at the four assessment time points. Before the intervention, depression severity scores in the aspirin and the placebo groups were 33.55 \pm 4.1 and $32.8 \pm 5.9$, respectively. Between-group difference at baseline was not statistically significant $(\mathrm{p}=0.509)$. The same finding was observed at two weeks after the beginning of the intervention $(\mathrm{p}=0.509)$. However, at four and eight weeks after the beginning of the intervention, depression in the placebo group was more severe than the aspirin group ( $\mathrm{p}<0.05$; Table 2). Data on the frequency of sertraline side effects are presented in Table 3. Most side effects on the aspirin group include $8 \%$ for Nausea, $8 \%$ for Dyspepsia and also $8 \%$ for Diarrhea. Although in placebo groups, headache has the highest rate of side effects at $12 \%$. In total, study groups did not significantly differ from each other regarding sertraline side effects ( $>0.05)$. In other words, the side effects of sertraline among patients who received aspirin were as similar as patients who received placebo. Also, Table 4 compares clinically significant response between groups at the four assessment time points. Study groups did not significantly differ from each other at two and four weeks after the intervention ( $\mathrm{p}=0.109$ for $2^{\text {nd }}$ week after beginning of the intervention). But Study groups significantly differed from each other at the eight weeks after the beginning of the intervention $(\mathrm{p}=0.008)$.

Table 1. Participants' demographic characteristics

\begin{tabular}{|c|c|c|c|c|}
\hline \multicolumn{2}{|l|}{ Variables } & Aspirin; n (\%) & Placebo; n (\%) & p-value* \\
\hline \multirow[t]{2}{*}{ Age (year) } & $40-50$ & $28(56)$ & $30(60)$ & \multirow{2}{*}{0.469} \\
\hline & $51-65$ & $22(44)$ & $20(40)$ & \\
\hline \multirow[t]{2}{*}{ Gender } & Male & $21(42)$ & $18(36)$ & \multirow[t]{2}{*}{0.539} \\
\hline & Female & $29(58)$ & $32(64)$ & \\
\hline \multirow[t]{4}{*}{ Marital Status } & Single & $13(26)$ & $12(24)$ & \multirow[t]{4}{*}{0.996} \\
\hline & Married & $28(56)$ & $29(58)$ & \\
\hline & widowed & $5(10)$ & $5(10)$ & \\
\hline & Divorced & $4(8 \%)$ & $4(8)$ & \\
\hline \multirow[t]{4}{*}{ Educational status } & Primary school & $11(22)$ & $4(8)$ & \multirow[t]{4}{*}{0.838} \\
\hline & Guidance school & $18(36)$ & $19(38)$ & \\
\hline & High school diploma & $16(32)$ & $18(36)$ & \\
\hline & Higher & $5(10)$ & $19(38)$ & \\
\hline \multirow[t]{3}{*}{ Monthly income (U.S. dollar) } & $<250$ & $33(66)$ & $38(76)$ & \multirow[t]{3}{*}{0.425} \\
\hline & $250-750$ & $14(28)$ & $11(22)$ & \\
\hline & $>750$ & $3(6)$ & $1(2)$ & \\
\hline \multirow[t]{2}{*}{ Comorbid anxiety } & Yes & $29(58)$ & $19(38)$ & \multirow[t]{2}{*}{0.638} \\
\hline & no & $21(42)$ & $31(62)$ & \\
\hline
\end{tabular}

* Chi-square test 


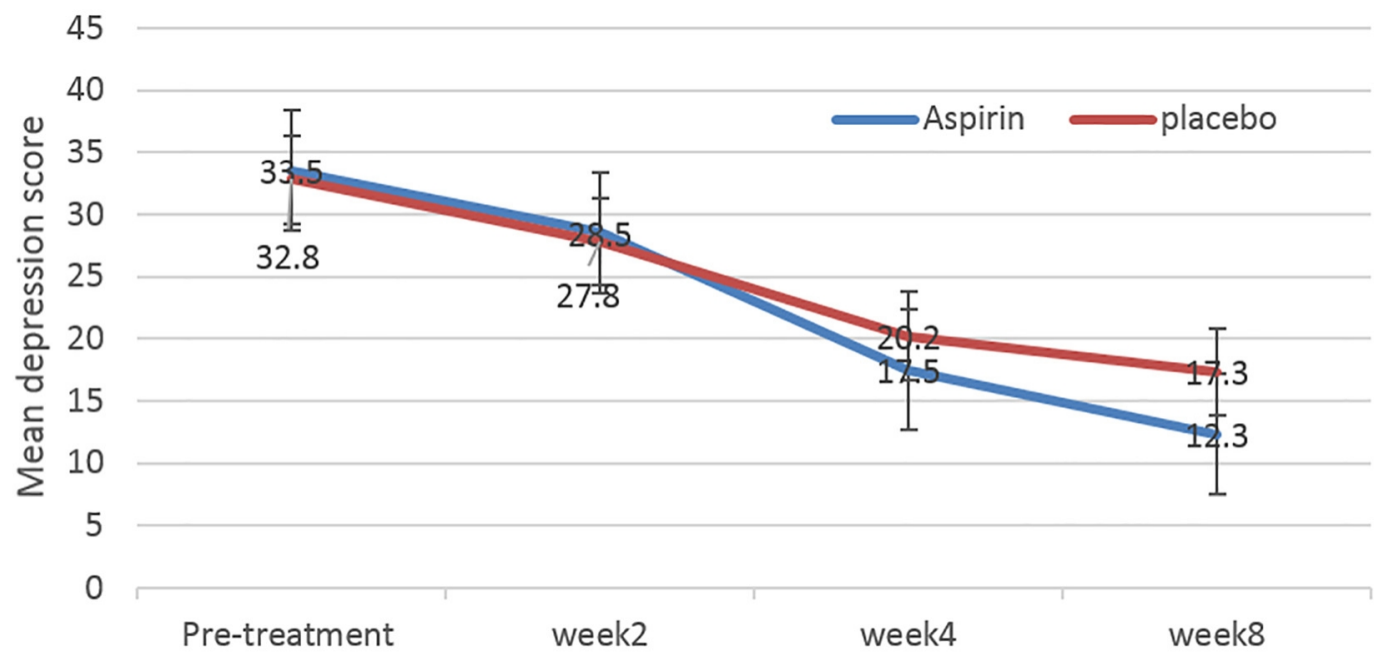

Figure 1. The variations of depression severity mean score across the four measurement time points

Table 2. Between-group comparison regarding the mean score of depression severity

\begin{tabular}{|l|l|l|l|}
\hline Times & Aspirin & Placebo & p-value* \\
\hline Pretest & $33.5 \pm 4.1$ & $32.8 \pm 5.9$ & 0.509 \\
\hline Two weeks after & $28.5 \pm 4.1$ & $27.8 \pm 5.9$ & 0.509 \\
\hline Four weeks after & $17.5 \pm 3.7$ & $20.2 \pm 5.8$ & $0.006^{\mathrm{a}}$ \\
\hline Eight weeks after & $12.3 \pm 3.4$ & $17.3 \pm 4.7$ & $0.001^{\mathrm{a}}$ \\
\hline The difference between pretest and the third posttest & $21.2 \pm 3.2$ & $15.6 \pm 3.9$ & $0.001^{\mathrm{a}}$ \\
\hline
\end{tabular}

* Independent-samples t-test

Table 3. The frequency distribution of drug side effects

\begin{tabular}{|l|l|l|l|}
\hline Side effects & Aspirin $\mathrm{n}(\mathrm{n}$ \%) & Placebo n (n \%) & $\mathrm{p}$-value* \\
\hline Nausea & $(8) 4$ & $(8) 4$ & $\mathrm{p}>0.99$ \\
\hline Agitation & $2(4)$ & $2(4)$ & $\mathrm{p}>0.99$ \\
\hline Headache & $3(6)$ & $6(12)$ & 0.486 \\
\hline Dyspepsia & $4(8)$ & $3(6)$ & $\mathrm{p}>0.99$ \\
\hline Diarrhea & $4(8)$ & $5(10)$ & $\mathrm{p}>0.99$ \\
\hline Decreased libido & $1(2)$ & $2(4)$ & $\mathrm{p}>0.99$ \\
\hline No side effects & $32(64)$ & $28(56)$ & 0.537 \\
\hline
\end{tabular}

* Independent-samples t-test

Table 4. The results of clinically significance of depression

\begin{tabular}{|l|l|l|l|l|}
\hline Time & Clinically response & Experimental group; $\mathbf{n}(\%)$ & Control group; $\mathrm{n}(\%)$ & p-value \\
\hline Two weeks after & Have & $0(0)$ & $0(0)$ & Not assigned \\
\cline { 2 - 4 } & Not have & $50(100)$ & $50(100)$ & \\
\hline Four weeks after & Have & $28(56)$ & $20(40)$ & 0.109 \\
\cline { 2 - 4 } & Not have & $22(44)$ & $30(60)$ & \\
\hline \multirow{2}{*}{ Eight weeks after } & Have & $42(84)$ & $30(60)$ & \\
\cline { 2 - 4 } & Not have & $8(16)$ & $20(40)$ & \\
\hline
\end{tabular}

* Chi-square test

\section{Discussion}

The aim of this study was to determine the effects of combined sertraline and aspirin therapy on depression severity among patients with MDD. Findings revealed that compared with sertraline-placebo therapy, combined use of aspirin and sertraline was associated with more significant improvement in depression symptoms. Moreover, the prevalence of the side effects of sertraline-placebo therapy was not greater than that of sertraline-aspirin therapy. These findings are in line with the findings of several earlier studies. For example, Berk et al. (2016) made a 
retrospective study on 19,114 elderly people, and found regular aspirin use (for five years) effective in significantly preventing the occurrence of depression (37). Rahola (2012) also reported that aspirin adjacent to antidepressants significantly improved depression symptoms (38). Another study also reported the effectiveness of fluoxetineaspirin in alleviating depression symptoms (39). Savitz et al. (2012) also conducted a study on 120 patients with bipolar disorder who were in depressive phase, and found that aspirin significantly reduced the side effects of antidepressants and significantly improved depression symptoms (36). Similarly, Almeida et al. (2012) reported that aspirin use significantly reduced the risk of developing depression among 3,687 older men with high plasma level of homocysteine (40). The first phase of a longitudinal study also illustrated aspirin use effective in alleviating both inflammatory and depression symptoms among young adults with MDD (41). Contrary to our findings, a study showed that combined use of aspirin (160 mg daily) and citalopram (20 mg daily) caused severe anxiety, akathisia, and suicidal behaviors among elderly people (30). The treatment of choice for depression management among elderly people is sertraline; thus, these conflicting findings can be attributed to the side effects of citalopram (30, 31). In addition, a retrospective study on 811 patients with MDD showed that combining nortriptyline and citalopram with NSAIDs did not significantly increase their antidepressant effects (32). These contradictory results can be attributed to the differences in the effects of different NSAIDs (33). Patients with MDD have high blood levels of C-reactive protein, tumor necrosis factor alpha, and interleukin (23). These factors adjust local and systemic inflammatory responses to microbial pathogens (42) Moreover, they affect the brain to prepare the body to fight infection and thereby, bring about behavioral symptoms of sickness $(24,42)$ such as fever, irritability, fatigue, and depressed mood (42). Therefore, symptoms such as irritability, fatigue, and depressed mood among patients with MDD may be due to chronic increased levels of these inflammatory markers. As an NSAID, aspirin lowers the levels of inflammatory mediators (such as prostacyclin and thromboxane) through inhibiting cyclooxygenase and thereby, reduces inflammation and alleviates behavioral symptoms of sickness (37). The present study had several limitations such as short follow-up period, limited age range of participants, and failure to assess the effects of other antidepressants.

\section{Conclusions}

Based on our results, we can conclude that Aspirin may have significant roles in preventing the progression or alleviating the symptoms of MDD through its anti-inflammatory and anti-oxidative effects. So, therapists can prescribe aspirin for reducing or alleviating the symptoms of MDD. Future studies are recommended to compare the effects of different doses of aspirin as well as the effects of different antidepressants in combination with aspirin on depression symptoms.

\section{Acknowledgments:}

We wish to express our gratitude to the Research Deputy of Kashan University of Medical Sciences, Kashan, Iran, for the financial support of this project. Moreover, authors are grateful to the staff of Kargarnejad Psychiatric Hospital.

\section{Conflict of Interest:}

There is no conflict of interest to be declared.

Authors' contributions:

All authors contributed to this project and article equally. All authors read and approved the final manuscript.

\section{References:}

1) Ferrari AJ, Charlson FJ, Norman RE, Patten SB, Freedman G, Murray CJ, et al. Burden of depressive disorders by country, sex, age, and year: findings from the global burden of disease study 2010. PLoS Med. 2013; 10(11): e1001547. doi: 10.1371/journal.pmed.1001547. PMID: 24223526, PMCID: PMC3818162.

2) Ustun TB, Ayuso-Mateos JL, Chatterji S, Mathers C, Murray CJ. Global burden of depressive disorders in the year 2000. Br J Psychiatry. 2004; 184: 386-92. doi: 10.1192/bjp.184.5.386. PMID: 15123501.

3) Sadeghirad B, Haghdoost AA, Amin Esmaeili M, Ananloo ES, Ghaeli P, Rahimi-Movaghar A, et al. Epidemiology of major depressive disorder in iran: a systematic review and meta-analysis. Int J Prev Med. 2010; 1(2): 81-91. PMID: 21566767, PMCID: PMC3075476.

4) Ferrari AJ, Somerville AJ, Baxter AJ, Norman R, Patten SB, Vos T, et al. Global variation in the prevalence and incidence of major depressive disorder: a systematic review of the epidemiological literature. Psychol Med. 2013; 43(3): 471-81. doi: 10.1017/S0033291712001511. PMID: 22831756. 
5) Sadock BJ, Sadock VA, Ruiz P. Kaplan \& Sadock's Synopsis of Psychiatry: Behavioral Sciences/clinical Psychiatry. Lippincott Williams \& Wilkins; 2014.

6) Association AP. Diagnostic and Statistical Manual of Mental Disorders (DSM-5): American Psychiatric Publishing; 2013. doi: 10.1176/appi.books.9780890425596.

7) Greenberg PE, Fournier AA, Sisitsky T, Pike CT, Kessler RC. The economic burden of adults with major depressive disorder in the United States (2005 and 2010). J Clin Psychiatry. 2015; 76(2): 155-62. doi: 10.4088/JCP.14m09298. PMID: 25742202.

8) Cipriani A, La Ferla T, Furukawa TA, Signoretti A, Nakagawa A, Churchill R, et al. Sertraline versus other antidepressive agents for depression. Cochrane Database Syst Rev. 2009; (2): CD006117. doi: 10.1002/14651858.CD006117.pub2. PMID: 19370626.

9) Vahia VN, Sonavane S, Gandhi A, Vahia I. Suicide and depression. J Indian Med Assoc. 2000; 98(5): 2326. PMID: 11002621.

10) Kedzior KK, Laeber LT. A positive association between anxiety disorders and cannabis use or cannabis use disorders in the general population--a meta-analysis of 31 studies. BMC Psychiatry. 2014; 14: 136. doi: 10.1186/1471-244X-14-136. PMID: 24884989, PMCID: PMC4032500.

11) Schreiber LR, Grant JE, Odlaug BL. Emotion regulation and impulsivity in young adults. J Psychiatr Res. 2012; 46(5): 651-8. doi: 10.1016/j.jpsychires.2012.02.005. PMID: 22385661, PMCID: PMC3334448.

12) Ono Y, Fujisawa D, Nakagawa A, Kikuchi T, Sado M. Cognitive therapy/cognitive behavior therapy for depression. Seishin Shinkeigaku Zasshi. 2013; 115(5): 539-46. PMID: 23855232.

13) Parker G, Roy K, Eyers K. Cognitive behavior therapy for depression? Choose horses for courses. Am J Psychiatry. 2003; 160(5): 825-34. doi: 10.1176/appi.ajp.160.5.825. PMID: 12727682.

14) Kanter JW, Baruch DE, Gaynor ST. Acceptance and commitment therapy and behavioral activation for the treatment of depression: description and comparison. Behav Anal. 2006; 29(2): 161-85. doi: 10.1007/BF03392129. PMID: 22478462, PMCID: PMC2223147.

15) Harley R, Sprich S, Safren S, Jacobo M, Fava M. Adaptation of dialectical behavior therapy skills training group for treatment-resistant depression. J Nerv Ment Dis. 2008; 196(2): 136-43. doi: 10.1097/NMD.0b013e318162aa3f. PMID: 18277222.

16) Smit A, Schene AH, Peeters FP, Spijker J. Tailored pharmacotherapy. Consultations about medication in a care programme for depression. Tijdschr Psychiatr. 2016; 58(12): 881-5. PMID: 27976786.

17) Casey G. Antidepressants: their role in treating depression. Nurs N Z. 2013; 19(8): 20-4. PMID: 24279052.

18) Liu CS, Adibfar A, Herrmann N, Gallagher D, Lanctôt KL. Evidence for Inflammation-Associated Depression. Curr Top Behav Neurosci. 2017; 31:3-30. doi: 10.1007/7854_2016_2. PMID: 27221622.

19) Durmaz O. Rheumatoid Arthritis, Depressive Symptoms and Inflammation. Noro Psikiyatr Ars. 2014; 51(2): 186. doi: 10.4274/npa.y7504. PMID: 28360624, PMCID: PMC5353099.

20) Alian S, Masoudzadeh A, Khoddad T, Dadashian A, Ali Mohammadpour R. Depression in hepatitis B and $\mathrm{C}$, and its correlation with hepatitis drugs consumption (interfron/lamivodin/ribaverin). Iran J Psychiatry Behav Sci. 2013; 7(1): 24-9. PMID: 24644496, PMCID: PMC3939977.

21) Benros ME, Waltoft BL, Nordentoft M, Ostergaard SD, Eaton WW, Krogh J, et al. Autoimmune diseases and severe infections as risk factors for mood disorders: a nationwide study. JAMA psychiatry. 2013; 70(8): 812-20. doi: 10.1001/jamapsychiatry.2013.1111. PMID: 23760347.

22) Lotrich FE. Major depression during interferon-alpha treatment: vulnerability and prevention. Dialogues Clin Neurosci. 2009; 11(4): 417-25. PMID: 20135899, PMCID: PMC3181938.

23) Prather AA, Vogelzangs N, Penninx BW. Sleep duration, insomnia, and markers of systemic inflammation: results from the Netherlands Study of Depression and Anxiety (NESDA). J Psychiatr Res. 2015; 60: 95102. doi: 10.1016/j.jpsychires.2014.09.018. PMID: 25307717, PMCID: PMC4250403.

24) Vane JR, Botting RM. The mechanism of action of aspirin. Thromb Res. 2003; 110(5-6): 255-8. doi: 10.1016/S0049-3848(03)00379-7. PMID: 14592543.

25) Seibert K, Masferrer JL. Role of inducible cyclooxygenase (COX-2) in inflammation. Receptor. 1994; 4(1): 17-23. PMID: 8038702.

26) Choi SH, Aid S, Bosetti F. The distinct roles of cyclooxygenase-1 and -2 in neuroinflammation: implications for translational research. Trends Pharmacol Sci. 2009; 30(4): 174-81. doi: 10.1016/j.tips.2009.01.002. PMID: 19269697, PMCID: PMC3379810.

27) Asanuma M, Miyazaki I, Ogawa N. Neuroprotective effects of nonsteroidal anti-inflammatory drugs on neurodegenerative diseases. Curr Pharm Des. 2004; 10(6): 695-700. doi: 10.2174/1381612043453072. PMID: 14965332. 
28) Kulmatycki KM, Jamali F. Drug disease interactions: role of inflammatory mediators in depression and variability in antidepressant drug response. J Pharm Pharm Sci. 2006; 9(3): 292-306. PMID: 17207413.

29) Rainsford KD. Anti-inflammatory drugs in the 21st century. Subcell Biochem. 2007; 42: 3-27. doi: 10.1007/1-4020-5688-5_1. PMID: 17612044.

30) Nebhinani N. Sertraline-induced galactorrhea: case report and review of cases reported with other SSRIs. Gen Hosp Psychiatry. 2013; 35(5): 576 e3-5. doi: 10.1016/j.genhosppsych.2012.10.010. PMID: 23260337.

31) Ghanizadeh A, Hedayati A. Augmentation of Citalopram with Aspirin for Treating Major Depressive Disorder, a Double Blind Randomized Placebo Controlled Clinical Trial. Antiinflamm Antiallergy Agents Med Chem. 2014; 13(2): 108-11. doi: 10.2174/1871523013666140804225608. PMID: 25091820.

32) Uher R, Carver S, Power RA, Mors O, Maier W, Rietschel M, et al. Non-steroidal anti-inflammatory drugs and efficacy of antidepressants in major depressive disorder. Psychol Med. 2012; 42(10): 2027-35. doi: 10.1017/S0033291712000190. PMID: 22391106.

33) Kohler O, Petersen L, Mors O, Gasse C. Inflammation and depression: combined use of selective serotonin reuptake inhibitors and NSAIDs or paracetamol and psychiatric outcomes. Brain Behav. 2015; 5(8): e00338. doi: 10.1002/brb3.338. PMID: 26357585, PMCID: PMC4559013.

34) Vasegh S, Baradaran N. Using the Persian-language version of the Beck Depression Inventory-II (BDI-IIPersian) for the screening of depression in students. J Nerv Ment Dis. 2014; 202(10): 738-43. doi: 10.1097/NMD.0000000000000183. PMID: 25208346.

35) Sharifi V, Mohammad Assadi S, Mohammadi MR, Amini H, Kaviani H, Semnani Y, et al. Structured Clinical Interview for DSM-IV (SCID): Persian translation and cultural adaptation. Iran J Psychiatry. 2007; 1: 46-8.

36) Savitz J, Preskorn S, Teague TK, Drevets D, Yates W, Drevets W. Minocycline and aspirin in the treatment of bipolar depression: a protocol for a proof-of-concept, randomised, double-blind, placebo-controlled, $2 \times 2$ clinical trial. BMJ Open. 2012; 2(1): e000643. doi: 10.1136/bmjopen-2011-000643. PMID: 22357572, PMCID: PMC3289990.

37) Berk M, Woods RL, Nelson MR, Shah RC, Reid CM, Storey E, et al. ASPREE-D: Aspirin for the prevention of depression in the elderly. Int Psychogeriatr. 2016; 28(10): 1741-8. doi: 10.1017/S104161021600079X. PMID: 27587328.

38) Wium-Andersen IK, Wium-Andersen MK, Jorgensen MB, Osler M. Anti-inflammatory treatment and risk for depression after first-time stroke in a cohort of 147487 Danish patients. J Psychiatry Neurosci. 2017; 42(5): 320-30. doi: 10.1503/jpn160244. PMID: 28632121, PMCID: PMC5573574.

39) Brunello N, Alboni S, Capone G, Benatti C, Blom JM, Tascedda F, et al. Acetylsalicylic acid accelerates the antidepressant effect of fluoxetine in the chronic escape deficit model of depression. Int Clin Psychopharmacol. 2006; 21(4): 219-25. doi: 10.1097/00004850-200607000-00004. PMID: 16687993.

40) Almeida OP, Flicker L, Yeap BB, Alfonso H, McCaul K, Hankey GJ. Aspirin decreases the risk of depression in older men with high plasma homocysteine. Transl Psychiatry. 2012; 2: e151. doi: 10.1038/tp.2012.79. PMID: 22872164, PMCID: PMC3432193.

41) Quinn AL, Dean OM, Davey CG, Kerr M, Harrigan SM, Cotton SM, et al. Youth Depression AlleviationAugmentation with an anti-inflammatory agent (YoDA-A): protocol and rationale for a placebo-controlled randomized trial of rosuvastatin and aspirin. Early Interv Psychiatry. 2015. doi: 10.1111/eip.12280. PMID: 26542332.

42) Dantzer R. Cytokine-induced sickness behavior: where do we stand? Brain Behav Immun. 2001; 15(1): 7 24. doi: 10.1006/brbi.2000.0613. PMID: 11259077. 